\title{
Obesity and Overweight Interconnected Hypertension-A Common Condition not to be Overlooked Since Pediatric Ages
}

\author{
Manuel Moya* \\ Chair of Technical Advisory Group on Nutrition, International Pediatric Association, \\ Pediatric Department. University Miguel Hernandez. Alicante. Spain
}

Received: November 29, 2014; Accepted: December 12, 2014; Published: December 17, 2014

*Corresponding author: Manuel Moya, Chair of Technical Advisory Group on Nutrition, International Pediatric Association, E-mail: Manuel.Moya@ umh.es

Since 1960s when the Framingham Heart Study demonstrated the linkage between hypertension and bodyweight the interest in this subject has grown ever since. Presently it lies in its growing prevalence, tracking to adult ages and risk for suffering from cardiovascular diseases and mortality.

The pathophysiology of this linkage is far beyond the present scope, but two facts are behind this: abdominal obesity and insulin resistance. Thus the consequences of both on sympathetic activity, leptin, renin-angiotensin system, sodium balance and epigenetic factors can have therapeutical implications [1].

In adults, blood pressure is regularly assessed, particularly if suffering from overweight, due to the fact that $75 \%$ of hypertension is related directly to obesity [2]. This is not the case in pediatric patients where primary hypertension is not very common and this together with other factors to be commented on later has led to a certain omission in regular pediatric checkups including obese children. However, according to the U.S. Preventive Service Task Force data, $11 \%$ of obese children have high blood pressure [3] and the increasing prevalence parallels the degree of obesity [4]. Prevalence in Europe is greater with a range of $35 \%$ to $39 \%$ over 25000 overweight or obese children according to three different ethnicities [5]. In different countries with different income rates this association of hypertension and obesity has also been demonstrated although sample size is smaller.

The blood pressure tracking or keeping in the same centile over time is probably the reason why adult cardiologists and WHO have claimed for prevention starting at pediatric ages. The prospective Finns-Study [6] showed how the hypertension and blood lipids increase as the BMI does. Another basic study carried out in Denmark [7] and after a follow up of 25 years of 275,000 children of 7-13 years pointed out that besides the tracking, for each unit of BMI-z score increment the coronary disease risk (lethal or not) also rises 17\%.

The interest of raised blood pressure in children is that this already implies an organic alteration although it is not clinically apparent. In a previous study of ours [8] on 101 obese children the thickness of interventricular septum and greater left ventricular mass were already present in comparison to the matched control group. This is in agreement with the findings that hypertension leads to left ventricular hypertrophy [9]. Another deleterious fact is the association with heart failure, coronary disease and death before 55 years of age which has been linked to hypertension in pediatric ages [10]. The Iceland study [11] on target-organ damage later in life at a mean of 58 years showed a significant correlation between both coronary disease and adult hypertension when the adolescent blood pressure was $>/=$ $95^{\text {th }}$ centiles. Karen McNiece [12] using the National High Blood Pressure norms, to be commented below, disclosed in adolescents not only the left ventricular hypertrophy but higher insulin levels with similar glucose levels compared to the controls [13]. This is an additional fact favoring insulin resistance with all the wellknown consequences

After this analysis the appropriate clinical identification of pediatric elevation in blood pressure or better pre-hypertension, is compulsory and to rule out causes other than obesity. It is worth checking the existence or not of the metabolic syndrome that will put over the track of other comorbidities. Due to the normal variation of blood pressure as growth progresses the norms given in 2004 by the Working Group on High Blood Pressure in Children and Adolescents [13] have been widely accepted. The cutoff values refer to gender and height (instead of age) of the child and results are registered in $50^{\text {th }}, 90^{\text {th }}, 95^{\text {th }}$ and $>95^{\text {th }}$ centiles for both systolic and diastolic values. Because the heights of children are grouped in percentiles ( $5^{\text {th }}$ to $\left.95^{\text {th }}\right)$ the use of computer programs facilitates the use of this important tool. Pre-hypertension is considered when the mean of the three (or two) figures for systolic or diastolic is between $90^{\text {th }}$ and $95^{\text {th }}$ centiles and hypertension when above $95^{\text {th }}$ centile. A simpler tool for identifying children and adolescents needing further evaluation of blood pressure was required. As implified table was originally conceptualized by Kaelberg and Pickett [14] with a reduction of 412 values checking over the original 3 and 4 tables. This idea was also taken by others and later on these simpler cutoff values were gathered by Ingelfinger [15] as in the table (Table 1). Concerning the method for measuring blood pressure traditionally the auscultatory techniques (mercury column or aneroid devices) have been recommended and can still be considered as a reference, but the device variability and the subjectivity that they imply and the frequent persistence of 
Table 1: Blood-Pressure Thresholds Indicating the Need for Further Evaluation, Intervention, or Both*.

\begin{tabular}{|c|cc|cc|c|c|}
\hline \multirow{2}{*}{ Years of Age } & \multicolumn{2}{|c|}{ Boys } & \multicolumn{2}{|c|}{ Girls } & Boys and Girls \\
& SBP & DBP & SBP & DBP & SBP DBP \\
\hline 3 & 100 & 59 & 100 & 61 & $\geq 100>60$ \\
\hline 4 & 102 & 62 & 101 & 64 & $\geq 100>60$ \\
\hline 5 & 104 & 65 & 103 & 66 & $\geq 100>60$ \\
\hline 6 & 105 & 68 & 104 & 68 & $\geq 105>70$ \\
\hline 7 & 106 & 70 & 106 & 69 & $\geq 105>70$ \\
\hline 8 & 107 & 71 & 108 & 71 & $\geq 105>70$ \\
\hline 9 & 109 & 72 & 110 & 72 & $\geq 110>75$ \\
\hline 10 & 111 & 73 & 112 & 73 & $\geq 110>75$ \\
\hline 11 & 113 & 74 & 114 & 74 & $\geq 110>75$ \\
\hline 12 & 115 & 74 & 116 & 75 & $\geq 115>75$ \\
\hline 13 & 117 & 75 & 117 & 76 & $\geq 115>75$ \\
\hline 14 & 120 & 75 & 119 & 77 & $\geq 115>75$ \\
\hline 15 & 120 & 76 & 120 & 78 & $\geq 120>80$ \\
\hline 16 & 120 & 78 & 120 & 78 & $\geq 120>80$ \\
\hline 17 & 120 & 80 & 120 & 78 & $\geq 120>80$ \\
\hline$\geq 18$ & 120 & 80 & 120 & 80 & $\geq 120>80$ \\
\hline
\end{tabular}

*The threshold for further evaluation or intervention is based on cut of points for hypertension from the fourth report of the National High Blood Pressure Education Program Working Group on High Blood Pressure in Children andAdolescents.DBP denotes diastolic blood pressure, and SBP systolic blood pressure [15]

the $5^{\text {th }}$ Korotkoff sound are giving way to the modern automated oscillometric devices.

Primary prevention actions are the same as those of pediatric obesity prevention but early stages of hypertension would imply a modification of the cardiovascular risks mostly carried out in individualized prevention. Preventing obesity from pregnancy, modification of lifestyle from early childhood and appropriate diet is the most efficient and normal way to keep blood pressure below $90^{\text {th }}$ centile. Treatment (ACE inhibitors) is restricted to severe cases $\left(95^{\text {th }}\right.$ centile $\left.+5 \mathrm{~mm} \mathrm{Hg}\right)$ or secondary hypertension.

The last message is that pediatric hypertension should not be missed nor mismanaged then the routine measuring of blood pressure in overweight/ obese children and adolescent is primordial. We should transmit the idea that all these agespecific requirements should not impair this important action as in some places or institutions occur nowadays [16]. This has a special connotation when dealing clinically with obesity comorbidities whether in children or adults. Due to important future consequences, this becomes crucial particularly when in the case of overweight or obesity a weight reduction can push back not only the present alterations but also the risk of a serious condition such as cardiovascular disease when these children reach adult ages.

\section{References}

1. Landsberg L, Aronne LJ, Beilin LJ, Burke V, Igel LI, Lloyd-Jones D, et al. Obesity-Related Hypertension: Pathogenesis, Cardiovascular Risk and Treatment - a Position Paper of the Obesity Society and the American Society of Hypertension. J Clin Hypertens (Greenwich). 2013; 15(1):14-33. doi: 10.1111/jch.12049.

2. American Heart Association. Overweight and Obesity Statistics - 2009 Update. Circulation 2009; 119: e21- e181.

3. Moyer VA. Screening for primary hypertension in children and adolescents: US Preventive Services Task Force Recommendation Statement. Ann Intern Med. 2013;159(9):613-619. doi:10.7326/00034819-159-9-201311050-00725.

4. Flynn JT. The changing face of pediatric hypertension in the era of childhood obesity epidemic. Pediatr Nephrol. 2013; 28(7):1059-1066. doi: 10.1007/s00467-012-2344-0.

5. Martin L, Oepen J, Reinehr T, Waboitsch M, ClaussnitzerG, Waldeck E, et al. Ethnicity and cardiovascular risks: evaluation of 40,921 normalweight, overweight or obese children and adolescents living in Central Europe. Int J Obes. 2014; doi: 10.1038/ijo.2014.167.

6. Juhola J, Magnussen CG, Viikari JS, Kähönen M, Hutri-Kähönen N, Jula A, et al. Traking of serum lipid, blood pressure and body mass index from childhood to adulthood. The cardiovascular risk in Young Finns-Study. J Pediatr. 2011; 159(4):584-590. doi: 10.1016/j.jpeds.2011.03.021.

7. Baker JF, Olsen LW, Sorensen TIA. Childhood body mass index and the risk of coronary heart disease in adulthood. N Eng J Med 2007; 357: 2329-2337. DOI: 10.1056/NEJMoa072515.

8. Moya M. Enfermedad cardiovascular. In Prevención precoz, prevención más eficaz. Un axioma para los estados comórbidos de la obesidad.Valencia (Spain): Real Academia de Medicina de la Comunidad Valenciana; 2014; 53-57.

9. Thompson M, Dana T, Bougatsos C, Blazina I, Norris SL. Screening for hypertension in children and adolescents to prevent cardiovascular disease. Pediatrics. 2013; 131(3):490-525. doi: 10.1542/peds.20123523.

10. Franks PW, Hanson RL, Knowler WC, Sievers ML, Bennet PH, Looker H. Childhood obesity, other cardiovascular risk factors and premature death. N Eng J Med 2010; 362:485-493. DOI: 10.1056/ NEJMoa0904130.

11. Erlingsdottir A, Indridason OS, Thorvaldsson O, Edvardsson VO. Blood pressure in children and target-organ damage later in life. Pediatr Nephrol. 2010; 25(2):323-328. doi: 10.1007/s00467-009-1350-1353.

12. McNiece KL, Gupta-Malhotra M, Samuels J, Bell C, Garcia K, Poffenbarger T, et al. Left ventricular hypertrophy in hypertensive adolescents. Analysis of risk by 2004 National High Blood Pressure Education Program Working Group staging criteria. Hypertension 2007; 50(2): 392-395.

13. National High Blood Pressure Education Program Working Group on High Blood Pressure in Children and Adolescents. Pediatrics. 2004; 114(2 Suppl 4th Report):555-576.

14. Kaelber DC, Pickett F. Simple table to identify children and adolescents needing further evaluation of blood pressure. PEDIATRICS. 2009; 123(6):e972 -e974doi:10.1542/peds.2008-2680.

15. Ingelfinger JR. The child or Adolescent with elevated Blood Pressure. N Engl J Med. 2014; 370:2316-2325, DOI: 10.1056/NEJMcp1001120.

16. Flechtner-Mors M, Wiegand S, Gellhaus I, Siefken-Kaletka H, Widhalm $\mathrm{K}$, Reinehr T, et al. Screening for co-morbidity in 65,397 obese pediatric patients from Germany, Austria and Switzerland: adherence to guidelines improved from the year 2000 to 2010. Obes Facts. 2013; 6(4):360-368. doi: 10.1159/000353397. 